\title{
Effect of length of steel fibers of waste tires on splitting tensile strength of concrete
}

\author{
Aneel Kumar Hindu ${ }^{1 *}$, Tauha Hussain Ali ${ }^{1}$, and Agha Faisal Habib ${ }^{1}$ \\ ${ }^{1}$ Department of Civil Engineering, Mehran University of Engineering and Technology, Jamshoro, \\ Pakistan
}

\begin{abstract}
The increase in volume of vehicles ultimately increases the number of waste tires. The proper disposal or reutilization of waste tires is a challenge. This study is aimed to utilize the steel fibers of waste tires as reinforcement in concrete. Concrete cylinders were cast with addition of different percentages of steel fibers $(0-2 \%)$ and length $(10-20 \mathrm{~mm})$. The fresh and hard properties of concrete reinforced with different percentages of steel fibers and lengths were observed. It is seen that splitting tensile strength of concrete increased with increase in the length of fiber and with the increase in the percentage of fiber. The inclusion of the fibers in concrete causes the reduction in the workability of concrete.
\end{abstract}

\section{Introduction}

About 77.6 million vehicles were produced worldwide in 2010, and that increased to 97.3 million in 2017 [1]. This increase in the production of vehicles caused the increase in the production of the waste tires. According to the U.S Department of Transportation, about 280 million waste tires are generated annually in the United States alone [2]. The disposal of such huge number of waste tires has already created serious environmental issues in many countries of Europe [3]. This problem is even more alarming in the developing countries like Pakistan where, even in the major cities, the municipal solid waste is not properly disposed of [4]. A typical waste tire weighs about $9.1 \mathrm{~kg}(20 \mathrm{lbs})$ and contains about $15 \%$ of steel $[2,5]$. To reduce the load of waste tire disposal, many researchers around the globe are investigating the possible utilization of the steel fibers of waste tires as reinforcement in concrete [6-10]. Aiello et al. evaluated the adhesion between the concrete matrix and steel fibers obtained from waste tires by performing pull-out tests [7]. The average length of the fiber was $26 \mathrm{~mm}$. They observed that the steel fibers from waste tires could give an effective contribution to the performance of the bond. This may be because of the irregular undulation of the steel fibers. They further observed that the pull-out behavior of Recycled Steel Fibers (RSF) and Industrial Steel Fibers (ISF) are the same. Graeff et al. observed that the fatigue performance of concrete reinforced with recycled fibers of the waste tire can be improved [8]. Zamanzadeh et al. demonstrated that the shear strength of reinforced concrete beams could be increased with RSF [9]. Caggiano et al. showed that ISF could be replaced by RSF in concrete [10]. Following the findings of the previous

\footnotetext{
* Corresponding author: aneel.kumar@faculty.muet.edu.pk
} 
researchers, this experimental study was conducted to evaluate the effect of length of steel fiber obtained from waste tires on splitting tensile strength of concrete.

\section{Materials and Methods}

Ordinary Portland cement utilized in the research was obtained from Lucky Cement Factory, Sindh. Various researchers have worked on this cement type and found that the cement complies with BS and ASTM Standards [11]. Coarse Aggregate of 20mm nominal aggregate size was obtained from Petaro Quarry in Sindh. Kumar et al. have discussed the properties of the quarry in detail [12]. Fine sand of Zone I was obtained from Bholari in Sindh. Various researchers have worked on the similar aggregates and found that these aggregates fulfill the requirement for typical civil engineering works [13, 14$]$.

The steel fibers used in this study were extracted from waste tires. The steel fibers were then cut into three lengths, i.e., $10 \mathrm{~mm}, 15 \mathrm{~mm}$, and $20 \mathrm{~mm}$. Fig. 1 shows steel fibers of 10 mm length.

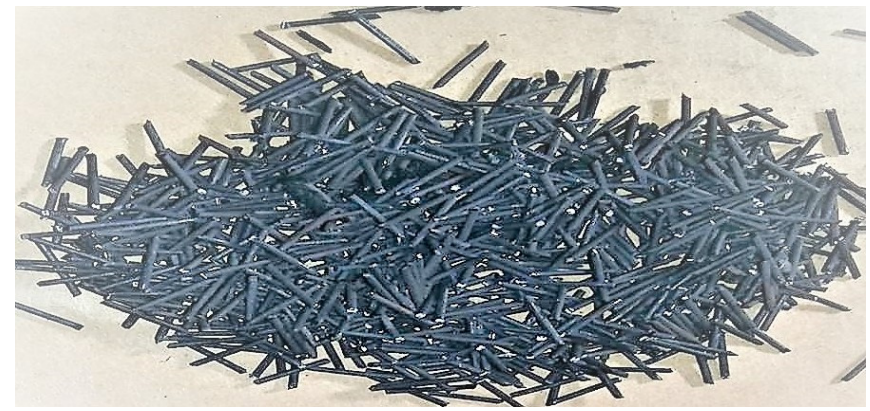

Fig. 1. Waste tire steel fibers of $10 \mathrm{~mm}$ length.

Sixty standard cylinders of $150 \mathrm{~mm}(6 ")$ diameter and $300 \mathrm{~mm}$ (12 ") length were cast. Among 60, 30 cylinders were cast with 1:2:4 concrete ratio and 30 with 1:1.5:3. Both the concrete was made with $0.5 \mathrm{w} / \mathrm{c}$ (water cement) ratio. Among 30 cylinders, three cylinders were cast with $0 \%$ steel fiber, nine cylinders with $1 \%$ steel fiber, nine with $1.5 \%$ steel fiber, and nine with $2 \%$ steel fiber. Among nine cylinders, three were cast with steel fibers having a length of $10 \mathrm{~mm}$, three with $15 \mathrm{~mm}$, and three with $20 \mathrm{~mm}$. All cylinders were cured for 28 days. Percentage of steel fiber was calculated utilizing Eq. 1.

$$
\% \text { of steel fiber }=(\text { Weight of steel fiber }) /(\text { Weight of fresh concrete })
$$

The splitting tensile strength of concrete (Ft') was obtained by utilizing Eq. 2, where $\mathrm{L}$ is the length of concrete cylinder and $\mathrm{D}$ is the diameter. $\mathrm{P}$ is compressive load applied to split concrete cylinder into two halves laterally. Universal Testing Machine (UTM) was used to apply the compressive load (P) at the rate of $0.3 \mathrm{~N} / \mathrm{mm}^{2} / \mathrm{sec}$.

$$
F_{t}^{\prime}=\frac{2 P}{\pi L D}
$$

\section{Results and discussion}

Fig. 2 and 3 show the effect of the length of steel fibers on Ft' of 1:2:4 and 1:1.5:3 concrete, respectively, having different percentages of steel fibers. The splitting tensile strength is based on the average value of three identical cylinders. 


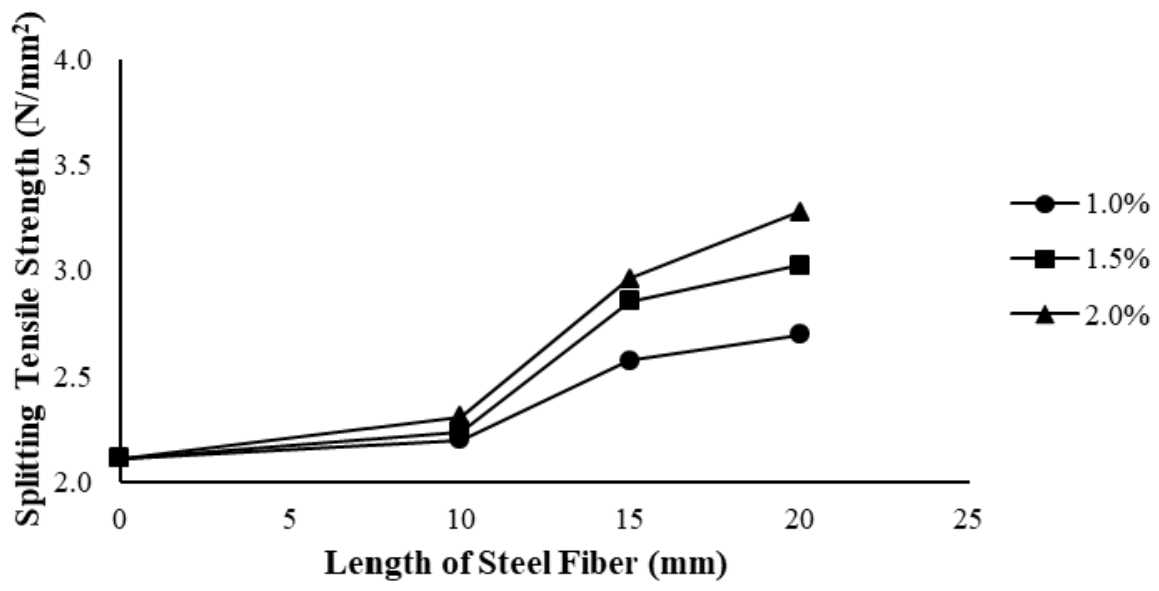

Fig. 2. $F t^{\prime}$ of 1:2:4 concrete vs. length of steel fiber.

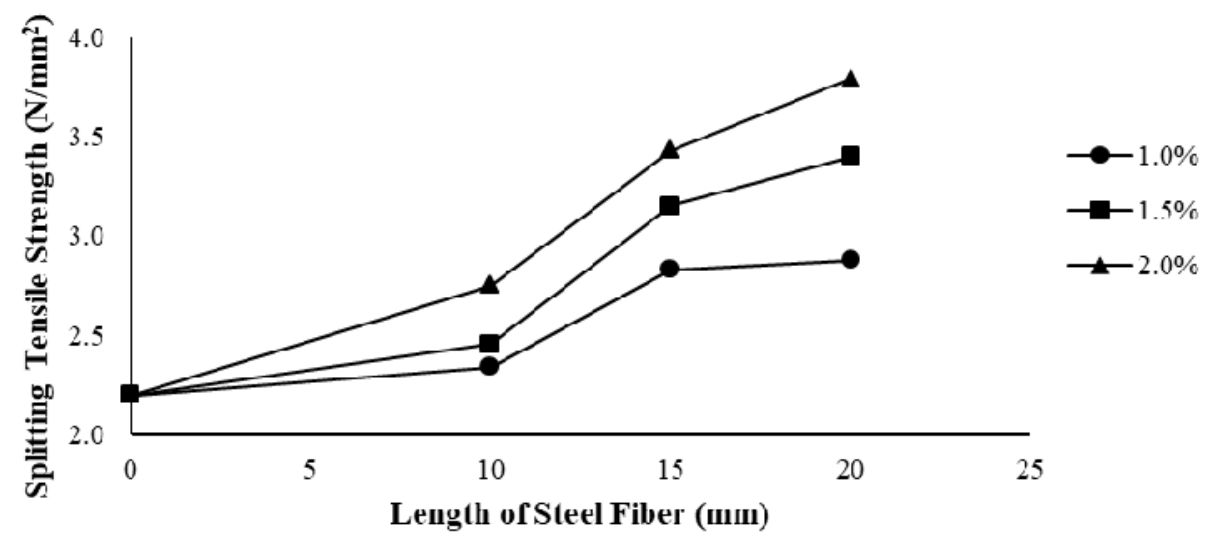

Fig. 3. $F t^{\prime}$ of 1:1.5:3 concrete vs. length of steel fiber.

It can be seen that, with the increase in the length of steel fibers, the Ft' increased. The trend of increase in Ft' remains high when the length of steel fiber increased from $10 \mathrm{~mm}$ to $15 \mathrm{~mm}$ and then remains gradual when the length of steel fiber increased from $15 \mathrm{~mm}$ to 20 $\mathrm{mm}$. The increase in $\mathrm{Ft}$ ' may be due to improvement in the mechanical properties of concrete, which might be occurred due to the addition of steel fibers [7].

Fig. 4 and 5 show the effect of percentage of steel fibers on Ft'of 1:2:4 and 1:1:5:3 concrete, respectively, having different steel fiber lengths.

It is observed that, with an increase in the percentage of steel fibers, the Ft' increased. The Ft' abruptly increased when the percentage of steel fiber increased from 1 to $1.5 \%$ and then remained gradual when the percentage of steel fiber increased from $1.5 \%$ to $2 \%$. It is interesting to note that, for the same percentage of steel fibers, the $\mathrm{Ft}$ ' remained high for long fibers. This may be because of a bridging effect explicated by the fibers in the zone of cracking [3].

Fig. 6 shows the percentage increase in Ft' when $1.5 \%$ of steel fiber is used with different lengths of steel fibers. Percentage increase in Ft' is calculated by utilizing Eq. 3, where A is Ft' without steel fibers, and B is Ft' with steel fibers.

$$
\% \text { increase in splitting tesile strength }=\frac{B-A}{A}
$$




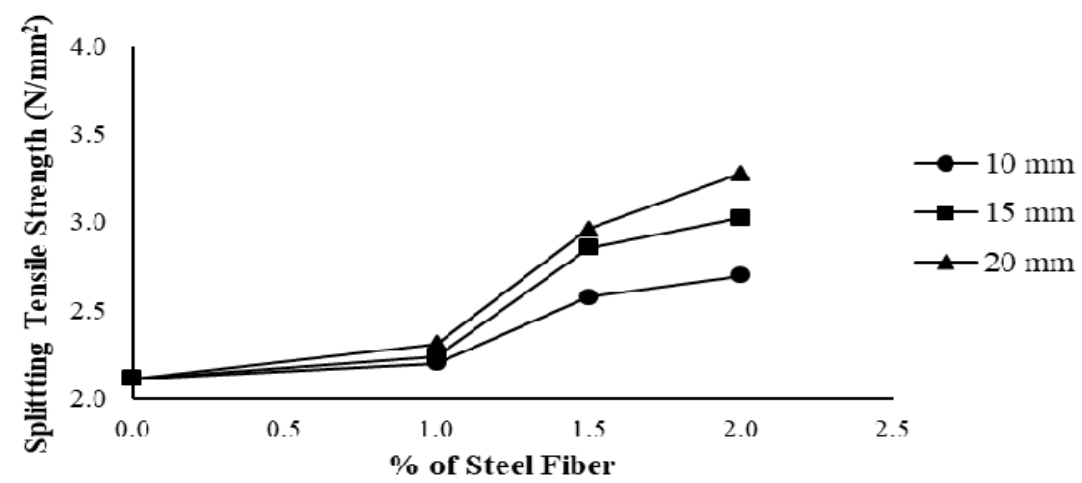

Fig. 4. Ft' of 1:2:4 concrete vs. percentage of steel fiber.

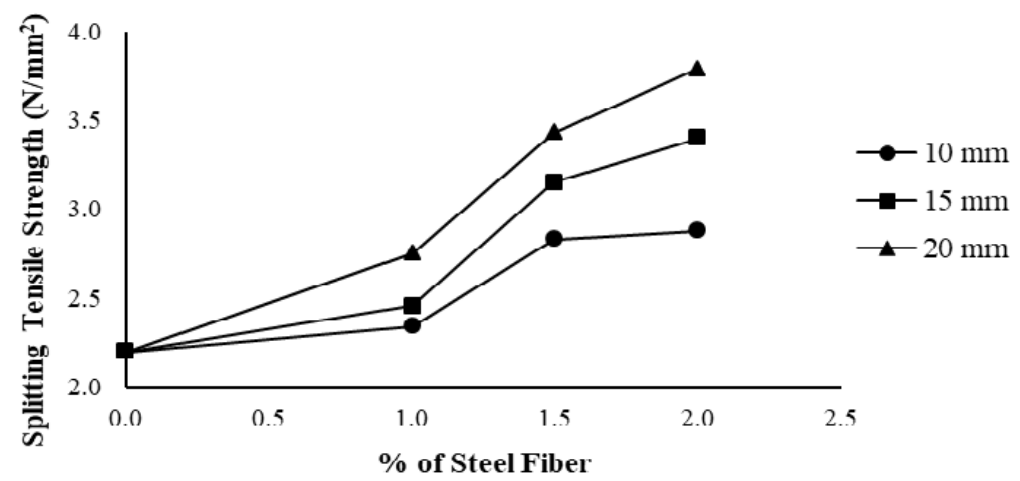

Fig. 5. $F t^{\prime}$ of 1:1.5:3 concrete vs. percentage of steel fiber.

It can be seen that the effect of steel fibers on Ft' remains higher in 1:1.5:3 concrete than that of 1:2:4. Similar behavior was observed for the $1 \%$ and $2 \%$ of steel fiber shown elsewhere [15]. This indicates that better interlocking forces might be generated between steel fiber and concrete having high cement/ aggregate ratio.

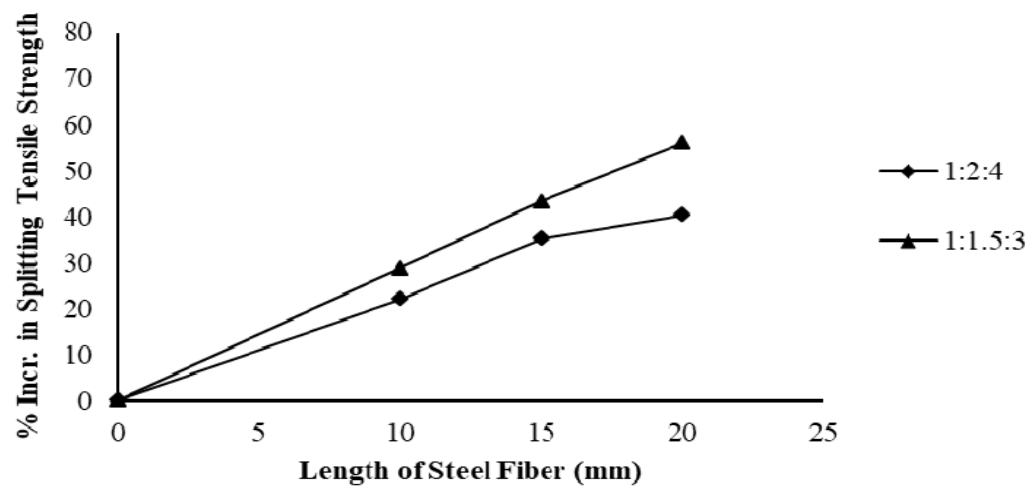

Fig. 6. Percentage increase in $F t^{\prime}$ vs. length of steel fibers.

Fig. 7 shows the effect of steel fibers on the workability of 1:1.5:3 concrete. The workability is measured in terms of the slump. It is seen that the workability of the concrete having steel fibers remains lower than that of conventional concrete. For the same length of steel fibers, the workability reduced with an increase in the percentage of steel fiber. It is exciting to note that, for the same percentage of steel fibers, the workability remained better 
for longer steel fibers. Almost the same pattern was observed for 1:2:4 concrete, shown elsewhere [15].

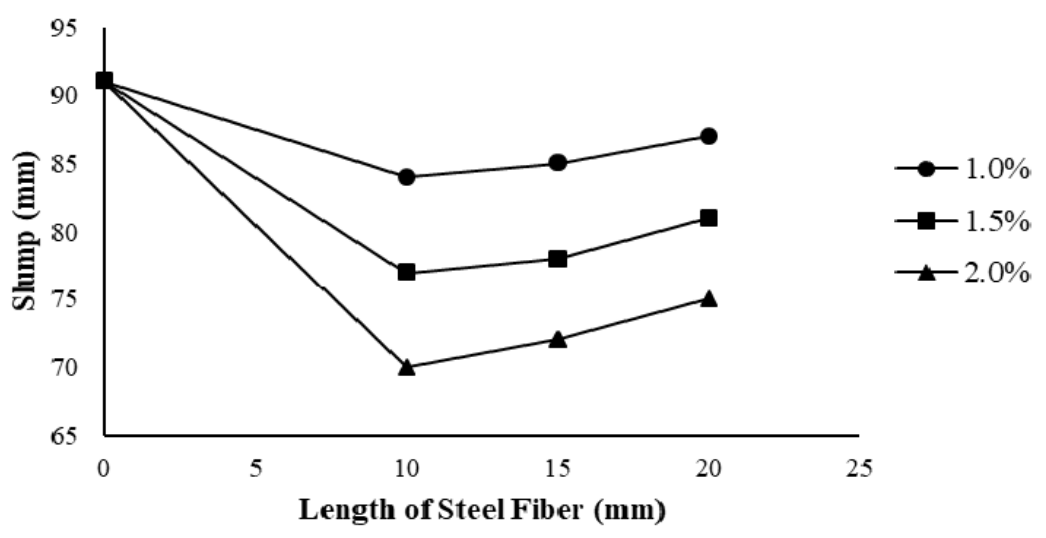

Fig. 7. Slump vs. length of steel fiber for 1:1.5:3 concrete.

\section{Conclusions}

An experimental study was conducted to evaluate the effects of length of steel fibers obtained from waste tires on the splitting tensile strength of the concrete. The following conclusions are drawn from this study. The conclusions are limited up to the range of steel fibers utilized in the study. The splitting tensile strength of concrete increased with the addition of steel fibers obtained from the waste tires. The higher the percentage of steel fibers, the higher the splitting tensile strength. For the same percentage of steel fibers, the splitting tensile strength remained high for the longer steel fibers. The effect of percentage increase in the splitting tensile strength of concrete remained more dominant in concrete having high cement/ aggregate ratio. The workability of the concrete reduced with the addition of the steel fibers. However, the reduction in the workability remained more for shorter fibers than that of longer fibers.

The authors are very grateful to the Pakistan Science Foundation for providing financial support for this research.

\section{References}

1. Statista. Worldwide automobile production from 2000 to 2017 (in million vehicles). Available at: https:/www.statista.com/statistics/262747/worldwide-automobileproduction-since-2000/ (2018)

2. Office of Research, Development, and Technology, Office of Safety. User Guidelines for Waste and Byproduct Materials in Pavement Construction. Available at: https://www.fhwa.dot.gov/publications/research/infrastructure/structures/97148/st1.cf $\mathrm{m}(2016)$

3. C. Centonze, M. Leone, M.A. Aiello, Con. Build. Mat. 36 (2012)

4. S. Javied, F. Hanan, S. Munawar, M. Qasims, M.M. Anees, M.U. Ghani, A. Azad, M. Khalid, I. Ullah, A. Ansar, Int. J. Sci. \& Eng. Res. 5, 12 (2014)

5. Scrap Tire News. Crumb Rubber Overview. Available at: http://www.scraptirenews.com/crumb.php 
6. R. Siddique, T.R. Naij, Waste Man. 24 (2004)

7. M.A. Aiello, F. Leuzzi, G. Centonze, A. Massezzoli, Waste Man. 29 (2009)

8. A.G. Graeff, K. Pilakoutas, K. Neocleous, M.V.N.N. Peres, J. Eng. Struc. 45 (2012)

9. Z. Zamanzadeh, L. Lourenco, J. Barros, Con. Build. Mat. 85 (2015)

10. A. Caggiano, P. Folino, C. Lima, E. Martinelli, M. Pepe, Con. Build. Mat. 147 (2017)

11. G.B. Khaskheli, A. Kumar, A. Shiakh, M.U.R. J. of Eng. \& Tech. 28 (2009)

12. A. Kumar, G.B. Khaskheli, I. Khoso, M.U.R. J. of Eng. \& Tech. 28 (2009)

13. R. Laghari, G.B. Khaskheli, A. Kumar, M.U.R.J. of Eng. \& Tech. 29 (2010)

14. A. Kumar, G.B. Khaskheli, L. Sanjarani, M.U.R.J. of Eng. \& Tech. 29 (2010)

15. A. Asif, W. Ahmed, A. Razzaque, M. Moosa, A. Ali, M.B. Zaid, (B.E. Thesis, M.U.E.T, 2012) 